GLADSTONE AND TRIBE ON THE FREPARATION, ETC. 561

XX.-Preparation of Copper-zine Couples.

By J. H. Glads tone, Ph.D., F.R.S., Fullerian Professor of Chemistry in the Royal Institution, and AyFRED Tribe, F.C.S., Lecturer on Chemistry in Dulwich College.

IN 1872 we communicated to the Royal Society the fact that zinc on which copper or some other negative metal was deposited in a spongy condition decomposes water at the ordinary temperature. This association of metals we subsequently termed the copper-zinc couple, an agent which has since been instrumental in the discovery of many new compounds and reactions.

Observations on the preparation of the couple have been published by Professor Thorpe and by ourselves, but the contemplation of a still larger extension of its use induced us to study more in detail the effect of the quantity and condition of the negative metal, with the practical object of arriving at the best formula for its preparation.

From the beginning we have used zinc in the form of foil. This condition possesses advantages. It gives a greater surface for equal weights than granulated zinc does, and admits of the use of a definite amount of surface, which is absolutely necessary where comparative results are required. The foil has generally been obtained from Messrs. Hopkin and Williams, 16, Cross Street, E.C. It contains about 1 per cent, of lead, the average amount of that metal which we found in several specimens of commercial zinc, and its thickness should be such that a square decimeter weighs about 2 grains. 


\section{Preparation of the Couple.}

Well crumple the required quantity of foil, and cut it into pieces of from 100 to 600 square millimeters. Place these in a vessel suitable for the projected operation, add a solution of copper sulphate, and allow the whole to remain until decolorised. Pour away the liquid, which has become a solution of zinc sulphate, and thoroughly wash the couple so made with water. Should more copper be required than is obtainable from the volume of copper sulphate solution necessary for the complete immersion of the zinc, another "deposition" can be effected by replacing the solution of zinc sulphate produced in the tirst operation by more copper sulphate.

\section{Influence of Quantity and Condition of the Copper.}

When zinc displaces copper from equal volumes of its sulphate of different strengths, the quantity of the metal deposited varies of course with the strength of the copper solution. Its condition also varies very considerably. Separated from weak solutions it is perfectly black and adheres firmly to the zinc, and when the solution is very weak the coating is almost impervious, the latter circumstance tending rather to the protection of the zinc than to the increase of its activity. Separated from very strong solutions, the copper is chocolate coloured or red, less adherent, and more spongy, and the crystals of the negative metal larger, which might with good reason be thought also to have an adverse influence upon the activity of the couple.

From considerations so complex as these, it became evident that the only way of arriving at a knowledge of the most effective association of the metals was by making a series of comparative trials. The experiments, the results of which are tabulated below, were therefore instituted. In each 5 meters of foil, 5 centimeters wide, weighing about 60 grams, were crumpled and cut into pieces of about 600 square millimeters. The couples were made by allowing the foil to decolorise equal volumes ( 450 c.c.) of copper sulphate of varying strengths, and their activity was ascertained by measuring the hydrogen evolved when placed in contact with distilled water. The action was allowed to go on for four hours before collecting the hydrogen, to allow of the hydrogenisation of the dissolved oxygen. The first reading was taken in $\mathbf{1 6}$ hours, the second in 4.0 hours. 


\begin{tabular}{|c|c|c|c|c|c|c|c|}
\hline \multirow{2}{*}{ 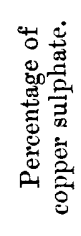 } & \multirow{2}{*}{ 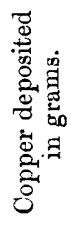 } & \multirow{2}{*}{ 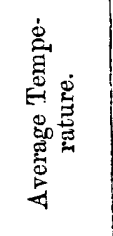 } & \multicolumn{2}{|c|}{$\begin{array}{l}\text { Hydrogen evolved } \\
\text { reduced to } 0^{\circ} \mathrm{C} \text {. } \\
\text { and } 760 \mathrm{~mm} \text {. }\end{array}$} & \multicolumn{3}{|c|}{$\begin{array}{l}\text { Arerage work done by each } \\
\text { gram of copper. }\end{array}$} \\
\hline & & & 16 hours. & 40 hours & $\begin{array}{l}\text { Between } \\
4 \text { and } 20 \\
\text { hours. }\end{array}$ & $\begin{array}{l}\text { Between } \\
20 \text { and } 44 \\
\text { hours. }\end{array}$ & $\begin{array}{l}\text { Between } \\
4 \text { and } 44 \\
\text { hours. }\end{array}$ \\
\hline 0.55 & 1 & $17 \cdot 6^{\circ} \mathrm{C}$ & $33 \cdot 5$ & $113 \cdot 3$ & $33 \cdot 5$ & $79 \cdot 8$ & $113 \cdot 3$ \\
\hline $1 \cdot 1$ & 2 & , & $92 \cdot 1$ & $255 \cdot 7$ & $46 \cdot 0$ & $81 \cdot 8$ & $127 \cdot 8$ \\
\hline $1 \cdot 65$ & 3 & ", & $156 \cdot 9$ & $415 \cdot 1$ & $52 \cdot 3$ & $86 \cdot 0$ & $138 \cdot 3$ \\
\hline $2 \cdot 2$ & 4 & , & $169 \cdot 1$ & $439 \cdot 3$ & $42 \cdot 3$ & $67 \cdot 5$ & $109 \cdot 8$ \\
\hline $2 \cdot 75$ & 5 & ", & $223 \cdot 6$ & $494 \cdot 7$ & $44 \cdot 7$ & $54 \cdot 2$ & $98 \cdot 9$ \\
\hline $3 \cdot 3$ & 6 & , & $224 \cdot 6$ & $546 \cdot 3$ & $37 \cdot 4$ & $53 \cdot 6$ & $91 \cdot 0$ \\
\hline $3 \cdot 85$ & 7 & 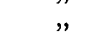 & $25 z \cdot 8$ & $599 \cdot 8$ & $36 \cdot 1$ & $49 \cdot 5$ & $85 \cdot 7$ \\
\hline $4 \cdot 4$ & 8 & 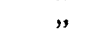 & $288 \cdot 5$ & $682 \cdot 3$ & $36 \cdot 0$ & $49 \cdot 2$ & $85 \cdot 3$ \\
\hline $4 \cdot 95$ & 9 & & $305 \cdot 4$ & $731 \cdot 2$ & $33 \cdot 9$ & $47 \cdot 3$ & $81 \cdot 2$ \\
\hline $6 \cdot 0$ & 11 & $18 \cdot 6^{\circ} \mathrm{C}$ & $352 \cdot 4$ & $889 \cdot 7$ & $32 \cdot 0$ & $48 \cdot 8$ & $80 \cdot \overline{8}$ \\
\hline $7 \cdot 1$ & 13 & , & $389 \cdot 8$ & $988^{\circ} 0$ & $29 \cdot 9$ & $46 \cdot 0$ & $76 \cdot 0$ \\
\hline $8 \cdot 2$ & 15 & $"$ & $468 \cdot 7$ & $1147 \cdot 3$ & $31 \cdot 2$ & $45 \cdot 2$ & $76 \cdot 4$ \\
\hline $9 \cdot 9$ & 18 & ", & $479 \cdot 8$ & $1183 \cdot 7$ & $26 \cdot 6$ & $39 \cdot 0$ & $65 \cdot 7$ \\
\hline $11 \cdot 5$ & 21 & ", & $494 \cdot 8$ & $1217 \cdot 5$ & $23 \cdot 5$ & $34 \cdot 4$ & $57 \cdot 9$ \\
\hline $13 \cdot 2$ & 24 & $"$ & $457 \cdot 3$ & $1161 \cdot 2$ & $19 \cdot 0$ & $29 \cdot 3$ & $48 \cdot 3$ \\
\hline
\end{tabular}

These results are shown graphically on the following page:-

A represents the 4th column of the table.

\begin{tabular}{|c|c|c|c|}
\hline B & $"$ & 5th & $"$ \\
\hline C & ", & 6th & $"$ \\
\hline D & " & 8th & ", \\
\hline
\end{tabular}

The horizontal figures show the copper, the vertical figures being the hydrogen.

The main result of these experiments is that the action is directly proportional to the time and the amount of copper deposited; but this is modified by at least three different circumstances :-

1. The gradual oxidation of the zinc, which must necessarily diminish the action proportionally in the higher members of the series, or in the longer time.

2. Something-probably the close texture of the coating-in the lower terms, which does not admit the full action to take place until we have a solution of about 1.6 per cent.

3. Something - probably the size of the base of the copper crystalswhich materially interferes after about 11 per cent.

Thus, so far as this series of experiments shows, a solution of 1.6 per cent. is the most active per amount of copper deposited, and one of about 11 per cent. does the most active work.

In order to ascertain more accurately the action due to the condition and magnitude of the copper crystals, we repeated our experiments, 


\section{4}

GLADSTONE AND TRIBE ON THE

8 depositing the same amounts of copper in a series of trials, but from different strengths of copper sulphate. The particulars are given in

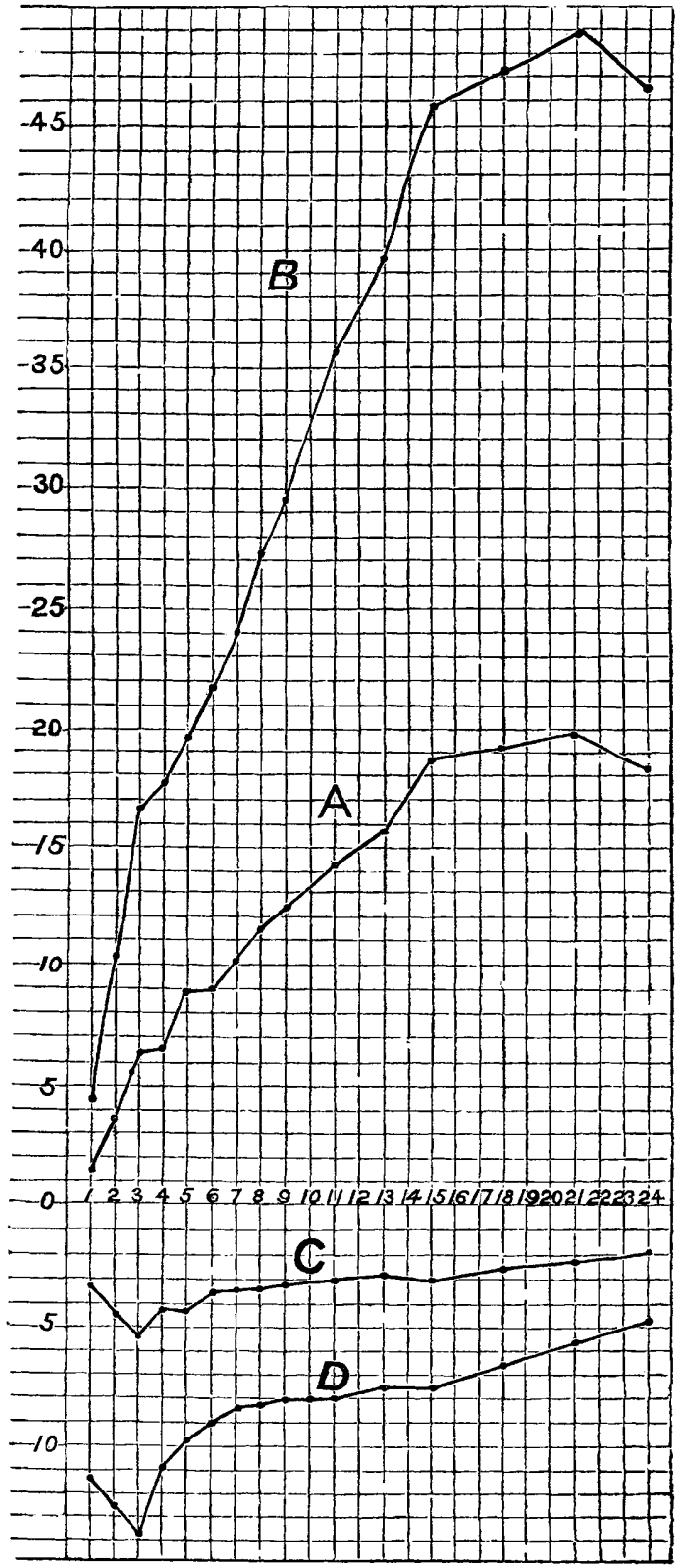


PREPARATION OF COPPER-ZINC COUPLES.

the subjoined table. The "number of depositions" means that one, two, \&c., equal volumes of copper sulphate solution were successively decolorised.

\begin{tabular}{|c|c|c|c|c|c|}
\hline \multirow{2}{*}{$\begin{array}{l}\text { Strength of } \\
\text { copper } \\
\text { sulphate. }\end{array}$} & \multirow{2}{*}{$\begin{array}{l}\text { Number } \\
\text { of } \\
\text { depositions. }\end{array}$} & \multirow{2}{*}{$\begin{array}{l}\text { Amount of } \\
\text { copper } \\
\text { in grams. }\end{array}$} & \multirow{2}{*}{$\begin{array}{c}\text { Average } \\
\text { temperature. }\end{array}$} & \multicolumn{2}{|c|}{$\begin{array}{l}\text { Hydrogen evolved re- } \\
\text { duced to } 0^{\circ} \mathrm{C} \text {. and } \\
760 \mathrm{~mm} .\end{array}$} \\
\hline & & & & 16 hours. & 40 hours. \\
\hline $\begin{array}{r}11 \cdot 0 \\
5 \cdot 5 \\
3 \cdot 7\end{array}$ & $\begin{array}{l}1 \\
2 \\
3\end{array}$ & $\begin{array}{l}20 \\
" \\
"\end{array}$ & $\begin{array}{c}17 \cdot 4^{\circ} \mathrm{C} . \\
" \\
"\end{array}$ & $\begin{array}{l}338 \cdot 4 \\
441 \cdot 8 \\
522 \cdot 0\end{array}$ & $\begin{array}{r}762 \cdot 3 \\
988 \cdot 1 \\
1124 \cdot 9\end{array}$ \\
\hline $\begin{array}{l}5 \cdot 5 \\
2 \cdot 7 \\
1 \cdot 8\end{array}$ & $\begin{array}{l}1 \\
2 \\
3\end{array}$ & $\begin{array}{l}10 \\
" \\
"\end{array}$ & $\begin{array}{l}", \\
",\end{array}$ & $\begin{array}{l}193 \cdot 9 \\
244 \cdot 3 \\
375 \cdot 9\end{array}$ & $\begin{array}{l}476 \cdot 5 \\
573 \cdot 8 \\
818 \cdot 6\end{array}$ \\
\hline $\begin{array}{r}11 \cdot 0 \\
2 \cdot 8 \\
1 \cdot 8 \\
1 \cdot 4\end{array}$ & $\begin{array}{l}1 \\
4 \\
6 \\
8\end{array}$ & $\begin{array}{l}20 \\
" \\
"\end{array}$ & $\begin{array}{c}18 \cdot 5^{\circ} \mathrm{C} . \\
" \\
"\end{array}$ & $\begin{array}{l}430 \cdot 8 \\
561 \cdot 9 \\
613 \cdot 4 \\
515 \cdot 6\end{array}$ & $\begin{array}{r}972 \cdot 7 \\
1335 \cdot 4 \\
1463 \cdot 2 \\
1273 \cdot 4\end{array}$ \\
\hline $\begin{array}{l}5 \cdot 5 \\
1 \cdot 8 \\
1 \cdot 4 \\
0 \cdot 7\end{array}$ & $\begin{array}{l}1 \\
3 \\
4 \\
8\end{array}$ & $\begin{array}{c}10 \\
" \\
"\end{array}$ & $\begin{array}{l}", \\
",\end{array}$ & $\begin{array}{l}300 \cdot 0 \\
4 \cdot 21 \cdot 4 \\
468 \cdot 7 \\
450 \cdot 0\end{array}$ & $\begin{array}{r}730 \cdot 4 \\
977 \cdot 0 \\
1118 \cdot 9 \\
1095 \cdot 5\end{array}$ \\
\hline
\end{tabular}

A glance at the results of each of the above series of experiments confirms the conclusion previously arrived at - that the most active couple is made when the solution contains about 1.4 to 1.8 per cent. of the salt.

The practical result is, therefore, that with the zinc employed the maximum effect is produced when the 20 grams of copper are deposited from about 1.4-1.8 per cent. solution of copper sulphate in from six to eight depositions.

Assuming 1.8 as the best strength of copper sulphate to employ, it became necessary to ascertain how much copper it was desirable to deposit upon a given surface of zinc. The following series of experiments was therefore made :- 


\begin{tabular}{|c|c|c|c|c|c|}
\hline \multirow{2}{*}{$\begin{array}{l}\text { Strength of } \\
\text { copper } \\
\text { sulphate. }\end{array}$} & \multirow{2}{*}{$\begin{array}{c}\text { Number } \\
\text { of } \\
\text { depositions. }\end{array}$} & \multirow{2}{*}{$\begin{array}{l}\text { Amount of } \\
\text { copper } \\
\text { in grams. }\end{array}$} & \multirow[t]{2}{*}{$\begin{array}{c}\text { Average } \\
\text { temperature. }\end{array}$} & \multicolumn{2}{|c|}{$\begin{array}{l}\text { Hydrogen evolved, re- } \\
\text { duced to } 0^{\circ} \mathrm{C} \text {. and } \\
760 \mathrm{~mm} .\end{array}$} \\
\hline & & & & 16 hours. & 40 hours. \\
\hline $\begin{array}{c}1 \cdot 8 \text { per cent. } \\
, \\
" \\
" \\
" \\
" \\
" \\
" \\
" \\
"\end{array}$ & $\begin{array}{r}1 \\
2 \\
3 \\
4 \\
5 \\
6 \\
7 \\
8 \\
9 \\
10\end{array}$ & $\begin{array}{r}3 \cdot 19 \\
6 \cdot 38 \\
9 \cdot 57 \\
12 \cdot 76 \\
15 \cdot 95 \\
19 \cdot 14 \\
22 \cdot 33 \\
25 \cdot 52 \\
28 \cdot 71 \\
31 \cdot 9\end{array}$ & $\begin{array}{c}16 \cdot 4^{\circ} \mathrm{C} . \\
" \\
" \\
" \\
" \\
" \\
" \\
" \\
"\end{array}$ & $\begin{array}{r}99 \cdot 1 \\
226 \cdot 5 \\
330 \cdot 4 \\
382 \cdot 3 \\
490 \cdot 8 \\
566 \cdot 4 \\
612 \cdot 9 \\
594 \cdot 1 \\
641 \cdot \cdot 2 \\
565 \cdot 8\end{array}$ & $\begin{array}{r}306 \cdot 3 \\
591 \cdot 1 \\
819 \cdot 1 \\
914 \cdot 7 \\
1131 \cdot 5 \\
1345 \cdot 7 \\
1297 \cdot 3 \\
1334 \cdot 9 \\
1443 \cdot 4 \\
1358 \cdot 5\end{array}$ \\
\hline
\end{tabular}

It is evident that the activity of the couple increases with the larger amount of copper till the sixth or seventh deposition, after which there is little or no advantage.

In consequence of these experiments, and in order to avoid multiplying depositions, we have adopted, as the most convenient method of obtaining a very active couple, a solution of 2 per cent. of copper sulphate, in sufficient quantity to yield 20 grams of copper on the zinc employed.

\section{Ethyl Hydride.}

In certain reactions it is of advantage, as in the preparation of the hydrides of the alcohol-radicles, that the couple should act upon mixtures of alcohol and haloid ethers in absence of water. All that is to be done in such cases is to wash the water couple a few times with alcohol, and add the haloïd compound alone or in admixture with alcohol. But it was necessary to ascertain whether the formula which gives a couple of maximum activity for water, would also yield the most effective couple for this class of decompositions.

Six experiments were made on the decomposition of precisely the same amounts of ethyl iodide and alcohol. The couples used were made of the same zinc foil, one-fourth of a meter in length, and were washed with alcohol. The volume of copper sulphate decolorised at each deposition measured 21 c.c., and the temperatare during the experiments varied from $15-16^{\circ} \mathrm{C}$. The results are given in the annexed table. 


\begin{tabular}{|c|c|c|c|c|c|}
\hline \multirow{2}{*}{$\begin{array}{l}\text { Percentage } \\
\text { of copper } \\
\text { sulphate. }\end{array}$} & \multirow{2}{*}{$\begin{array}{c}\text { Number } \\
\text { of } \\
\text { depositions. }\end{array}$} & \multirow{2}{*}{$\begin{array}{l}\text { Copper } \\
\text { in } \\
\text { grams. }\end{array}$} & \multicolumn{3}{|c|}{ Ethyl hydride in c.c. } \\
\hline & & & 15 mins. & 1 hour. & 25 hours. \\
\hline $\begin{array}{l}2 \\
" \\
" \\
" \\
"\end{array}$ & $\begin{array}{l}1 \\
2 \\
3 \\
4 \\
5 \\
6\end{array}$ & $\begin{array}{l}\cdot 166 \\
\cdot 333 \\
\cdot 499 \\
\cdot 666 \\
\cdot 832 \\
\cdot 999\end{array}$ & $\begin{array}{c}7^{*} \\
23 \\
56 \\
64 \\
71 \\
68\end{array}$ & $\begin{array}{r}28 \\
56 \\
94 \\
115 \\
113\end{array}$ & $\begin{array}{l}514 \\
535 \\
632 \\
692 \\
722 \\
767\end{array}$ \\
\hline
\end{tabular}

The augmentation of action for equal increments of copper is more rapid here than in the series of experiments with water. For practical purposes, however, it may be taken that a couple which decomposes the maximum amount of water in a given time would also yield the greatest amount of ethyl hydride by its action on a mixture of ethyl iodide and alcohol.

The time taken up in depositing a given weight of copper depends very mach upon the number of depositions. With the view of ascertaining more specifically whether these could be lessened with practical advantage, we deposited the same weight of copper on equal quantities of the foil, firstly from a 6 per cent. solution in two depositions, secondly from a 2 per cent. solution in six depositions. The results were as under:-

6 per cent. solution in 3 Hydrogen in 16 hours, 745 c.c. two depositions ...,$\quad 40$, 1430 c.c.

2 per cent. solution in $\}$ Hydrogen in 16 hours, 878 c.c. six depositions .... $, \quad 40 \quad, 1515$ c.c.

6 per cent. solution in Ethyl hydride in 1 hour, 94 c.c. two depositions.... $\}^{\prime \prime 2}, 25$ hours, 620 c.c.

2 per cent. solution in $\}$ Ethyl hydride in 1 hour, 147 c.c. six depositions .... " "25 hours, 628 c.c.

It is evident that a 2 per cent. solution gives the better result.

$$
\text { Dry Couples. }
$$

In the preparation of certain of the organo-zinc compounds and other reactions, it is absolutely necessary to employ the couple in a dry condition. For this purpose wash the well-washed water couple with alcohol (strong methylated), then with ether. Pour off the ether, and dry the couple in a current of hydrogen-gas, $\dagger$ heating the

* The solubility of ethyl hydride in the mixture doubtless affected this number.

† Hitherto we have used carbonic acid. We now recommend hydrogen or dry coal gas, because we have noticed that the couple when heated at all strongly in presence of carbonic acid, decomposes it, yielding carbonic oxide and oxide of zinc, the formation of the latter of which lessens the activity of the couple. 
vessel containing it over a lamp. When the ether has escaped, heat the couple a little more strongly, keeping it gently agitated. At a certain point the couple breaks up, and becomes reduced to about a tenth of its original bulk. It should be granular and not powdery. Allow it to cool in hydrogen.

The time required to convert a given weight of ethyl iodide into zinc ethiodide (which may be taken as a typical action) by means of the dry couple, varies very much with the amount of the negative metal. The results of some of our experiments on this point are below. In each experiment half a meter of the foil was used, the volume of copper sulphate for each deposition being 42 c.c. The flasks containing the couples and 5 c.c. of ethyl iodide were attached to an inverted condenser, and heated by immersion in boiling water. As soon as the dropping ceased from the condenser, the conversion was deemed complete.

\begin{tabular}{c|c|c|c}
\hline $\begin{array}{c}\text { Percentage } \\
\text { of } \\
\text { copper sulphate. }\end{array}$ & $\begin{array}{c}\text { Number } \\
\text { of } \\
\text { depositions. }\end{array}$ & $\begin{array}{c}\text { Copper deposited } \\
\text { in } \\
\text { grams. }\end{array}$ & $\begin{array}{c}\text { Time for conversion } \\
\text { into ethiodide in } \\
\text { minutes. }\end{array}$ \\
\hline $1^{*}$ & 1 & $0 \cdot 083$ & 14 minutes. \\
1 & 2 & $0 \cdot 333$ & $12 \cdot 5$ and 14 \\
2 & 1 & $0 \cdot 333$ & 6 and 9 \\
2 & 2 & $0 \cdot 666$ & 9 \\
2 & 4 & $1 \cdot 333$ & 26 \\
\hline
\end{tabular}

Here it is seen that one deposition from a 2 per cent. solution of copper sulphate gives a dry couple of maximum activity. The weight of zinc used to the copper is in the ratio of $1: 0.036$. The reason why so small a quantity of the negative metal produces the best result, is not difficult to give. On drying, the projecting copper crystals doubtless, when of any length, undergo disintegration, thereby breaking metallic contact with the zinc. The hases, however, of these crystals adhere firmly, and this is probably the only portion of the deposited copper which assists in the action.

The quantity of gaseous hydrocarbons produced in the first three of the above experiments was nearly the same, measuring 4.7 c.c., which means a loss of about 0.03 gram of ethyl iodide out of 9 grams. To obtain a knowledge of the actual advantage of the couple, an experiment was made as follows. Half a meter of the zinc foil was crumpled and cut into small pieces, washed with alcohol and ether, and reduced while hot by agitation to about the same bulk as were the couples. The time required to convert 5 c.c. $(9.5$ grams) of ethyl

* Only half the volume was used in this experiment. 
iodide at abont $100^{\circ} \mathrm{C}$., was about 3 hours and 20 minutes, and the amount of hydrocarbons collected measured 164 c.c., which means a loss of 1.14 gram of the iodide. Thus zinc containing about 1 per cent. of the negative metal lead, takes 26.5 times as long in doing the same work as does the dry couple, and causes 34.5 times the loss by destroying the substance it is desirable to conserve.

Were pure zinc employed, the difference would doubtless be even more strongly marked, because after the surface of the zinc has been slightly corroded, any lead present as an impurity must act, to a greater or less extent, the part of the copper in our couple. This supposition was subsequently confirmed by the following experiment:-

Some zinc was reduced by ourselves, 'starting with pure sulphate, and without touching anything but porcelain. A quantity of this zinc was granulated, and the finer portions were picked out. 10.31 grams were heated for $6 \frac{1}{2}$ hours with 5 c.c. of ethyl iodide. The flask was then washed out with anhydrous ether, water was added, the solution evaporated, and the zinc in solution deternined. Zinc oxide found 0.0051 gram. The same zinc was then conpleised, and heated with the same amount of ethyl iodide. In 3 hours 25 minutes, the action was over, the flask was washed out with ether, the solution added to water, and precipitated by sodium carbonate. Zinc oxide found $=2.692$ grams. These data give for equal times an amount of action 1004 times greater in the case of the couple than in the case of pure zinc.

In the conversion of ethyl iodide into the ethiodide on a larger scale, the temperature rises so quickly as frequently to necessitate the application of cold water to the flask. We have noticed that the mere heating of the ethiodide to $100^{\circ} \mathrm{C}$. slowly evolves hydrocarbons. To prevent loss therefore, the conversion should be got over as quickly as possible. We have noticed too, that sometimes a small quantity of free zinc-ethyl in addition to the ethiodide is formed in the reaction, especially when it is carried on on a large scale, which flowing down the inner tabe of the condenser, may give the impression of the nonconversion of the whole of the iodide.

We do not recommend granulated zinc for larger operations, from the impracticability of ascertaining the surface of any given weight of it; but we see no reason why the ordinary thin sheet zinc of commerce should not be used, which would avoid the employment of the more expensive foil.

In au experiment employing 4 meters of foil coated with $6 \cdot 72$ grams of copper deposited from a 2 per cent. solution of copper sulphate, and 60 c.c. of ethyl iodide ( 115 grams), we obtained within two hours, which includes the preparation of the couple, the conversion 


\section{0}

into ethiodide, and subsequent distillation, 40 grams of perfectly clear zinc-ethyl, or 88.4 per cent. of the theoretical quantity, which is 18.7 per cent. in excess of what we obtained in the best operation, on onetwelfth the scale, described in our original paper on this subject.

The following are the recommendations, relative to the best proportions of zinc, and the strength and quantity of the copper sulphate to be employed in the preparation of copper-zinc couples, based on our results.

Dry Couples.-Add 84 c.c. of a 2 per cent. solution of anhydrous copper sulphate to 1 meter of foil 5 centimeters wide, that is 500 square centimeters, exposing on the two sides a surface of 1000 square centimeters, crumpled as directed.

Couples wet with Alcohol or Water.-To 1 meter of the same foil, add 84 c.c. of a 2 per cent. solution of the sulphate, allow the solution to decolorise, pour off the zinc sulphate, and repeat five times.

We would now draw attention to a few points which appear of special interest in connection with the action of the couple.

It is known that zinc does not decompose liquid water at any temperature at the ordinary pressure, but that the couple does even at as low a temperature as $2^{\circ} \mathrm{C}$. It is known also that water is electrolyzed by a small battery power. Again, zinc at the ordinary temperature has no action upon a mixture of ethyl iodide and alcohoi, whereas the couple decomposes it readily. Yet no signs of electrolysis could be detected when this mixture was submitted to the action of 100 Grove's cells, even when the platinum electrodes employed were very close together.

It would appear then that this simple association of metals is more powerful for effecting the decomposition of certain organic bodies, than the electric power derivable from a large battery. 